\title{
Adoption, Use and Environmental Impact of Feminine Hygiene Products among College Going Girls of Udaipur, India
}

\author{
Sirisha Deepthi Sornapudi*, Meenu Shrivastava, Shalini Soni and Shweta Jha
}

Department of Textiles \& Apparel Designing, College of Community and Applied Sciences, MPUAT, Udaipur, India

*Corresponding author

\begin{abstract}
A B S T R A C T
Keywords

Owing to gaps in research studies regarding menstrual hygiene among college going students, this study was planned to gather information regarding awareness of feminine hygiene products in the market, availability, popularity, adoption, usage and disposal

Menstrual hygiene,

Feminine hygiene

products, Environment pattern of feminine hygiene products (FHP). The findings indicate that very few of the college going students knew of tampons and menstrual cup. Ultra thin sanitary pad was the only absorbent used during menstrual cycle. The respondents were unwilling to switch over to other types of FHP; reasons for non-adoption were also indicated. A majority of the respondents knew of the environmental hazards of FHP. Respondents indicated that proper disposal is the need of the hour. There is an urgent need to formulate an ideal disposal pattern than simply wrapping the used sanitary pads and throwing in the dustbin. A year's worth of a typical feminine hygiene product leaves a carbon footprint of $5.3 \mathrm{~kg}$ $\mathrm{CO}_{2}$ equivalents. Efforts are needed to promote the use of sustainable alternatives and to educate the community at large regarding the appropriate usage, disposal which may help in reducing the environmental pollution.
\end{abstract}

\section{Introduction}

Feminine hygiene products are personal care products used by women during menstruation, which can be either disposable (sanitary napkins, tampons and panty liners) or reusable (menstrual cups, cloth pad). A significant portion of the Indian disposable hygiene market, accounts for these feminine hygiene products. Euromonitor, a market research company, estimates that the Indian feminine hygiene product market has reached Rupees 22.21 billion ( $\$ 340$ million) in 2017 and is expected to reach Rupees 34.68 billion $(\$ 522$ million) by 2020. Increase in demand was attributed to rising income and choice of a comfortable and convenient lifestyle. Despite demand, the penetration rate of the sanitary napkins market was only 24\% in 2014 and is expected to grow to $42 \%$ by 2018 . (Nonwovens Industry Magazine, March 2017).

Several studies point out to the fact that the use of sanitary napkins have increased. A study conducted in the slums of Hyderabad reports that there was a high usage of sanitary pads (56 percent), suggesting that 
development initiatives have percolated down to the urban poor (Garikipati and Boudot, 2017). A meta-analysis of menstrual hygiene management (MHM) among adolescent girls in India, by Van Eijk AM et al., (2016) reported that commercial pad use was more common among urban girls than rural girls and inappropriate disposal was common.

A lot of research work has been reported on school going and adolescent girls with regards to their menstrual hygiene. There was a dearth of information regarding the menstrual practices of college going girls, hence a study was planned to gather information regarding awareness of available feminine hygiene products in the market along with the availability, popularity, adoption, usage and disposal pattern.

\section{Materials and Methods}

This study was undertaken to know the menstrual hygiene practices followed by college going students of Udaipur city, Rajasthan covering two degree colleges namely College of Community and Applied Sciences under MPUAT and College of Science under Mohanlal Sukhadia University. A total of 40 students were interviewed in July 2018, using a pretested questionnaire. Responses were coded, data was tabulated and analysed using appropriate statistical tests.

\section{Results and Discussion}

The respondents who participated in the study were in the age range of 16 to 31 years of age $(n=40)$. All $(100 \%)$ of them were aware of feminine hygiene products (FHP) and they were frequent users of internet. Figure 1 shows the respondents awareness regarding FHP. It is evident that a majority $(47.5 \%)$ of them were aware of sanitary napkins; 20 per cent of them had knowledge of all types of absorbents viz. sanitary napkins, tampons, menstrual cup and cloth; very few of the respondents $(7.5 \%)$ knew of both sanitary napkins and tampons. Cent percent of the respondents used only sanitary napkins of various brands for their menstrual care as predicted by Garikipati and Boudot (2017). None of the respondents have used either tampons or menstrual cup. The current study results are in contrast to that of Kumar et al., (2016), who reported that 62.5 per cent of the urban adolescent girls of Bareilly (UP), aged between 10 to 19 years used sanitary pads, 34.6 per cent used old cloth, 2.8 per cent used new cloth. It could be reasoned out that urbanization, access to knowledge materials and exposure to media has increased the respondent's awareness on personal as well as feminine hygiene products.

The subject's knowledge regarding menarche and suitable feminine hygiene products is indicated in Table 1. It is evident that mothers (40\%) played a major role in educating their daughters. In addition, the respondents revealed that other family members like grandmother, sister and aunt were instrumental in initiating basics of menstrual hygiene. School, friends and mass media also played a significant role in information dissemination regarding menstrual hygiene.

A majority (75\%) of the respondents buy their own sanitary napkins of ultra-thin variety, while family members $(25 \%)$ sometimes help in purchase of FHP. The result corresponds with the prediction cited in a report titled 'Feminine Hygiene Market India Industry Analysis 2017-2021' (The Small Business Newswire report, 2017), where the acceptance of ultra thin sanitary napkins was found to be more among urban girls. All the respondents reported that readymade sanitary pads were easily available in their local shops and that they had no difficulty in procuring them which indicates that the penetration rate of sanitary pads in urban area is more. 
Fig.1 Awareness on type of FHP products

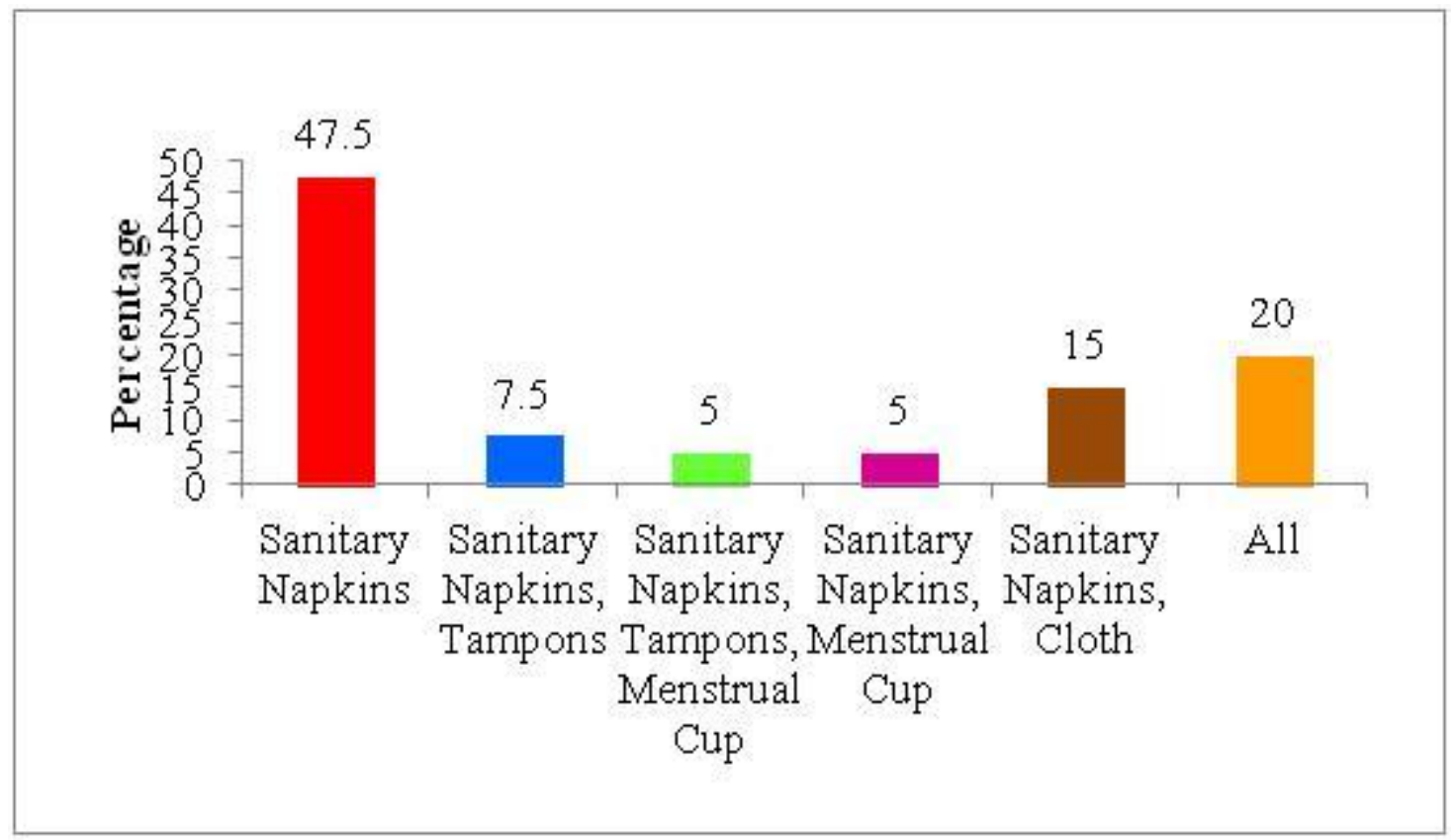

Fig.2 Factors influencing the choice of sanitary pads among respondents

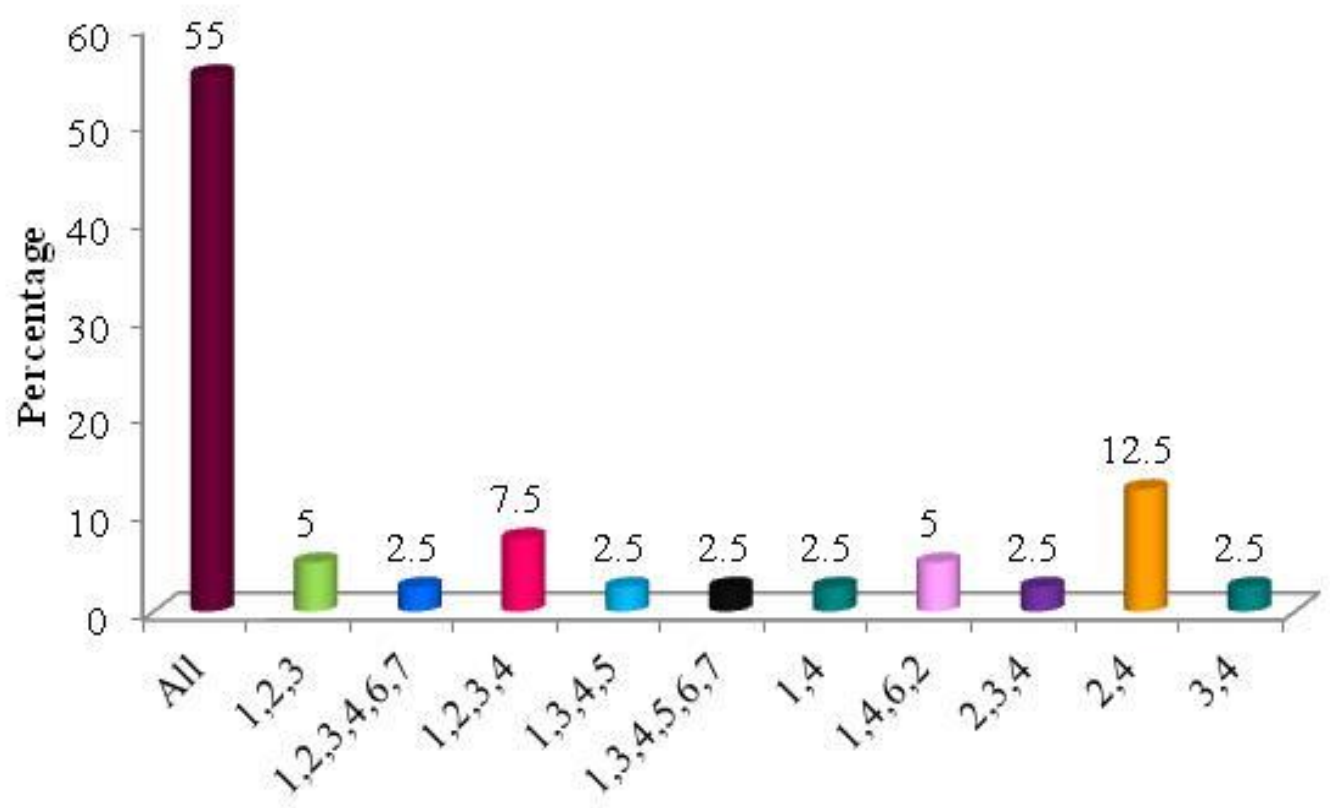
$1=$ Hygienically safe
$5=$ Dry feel
2 = Easy to use
$6=$ Thin
$3=$ Easily available
$7=$ Easy disposal
$4=$ Comfortable
All $=1$ to 7 
Fig.3 Reasons for not adopting other feminine hygiene products

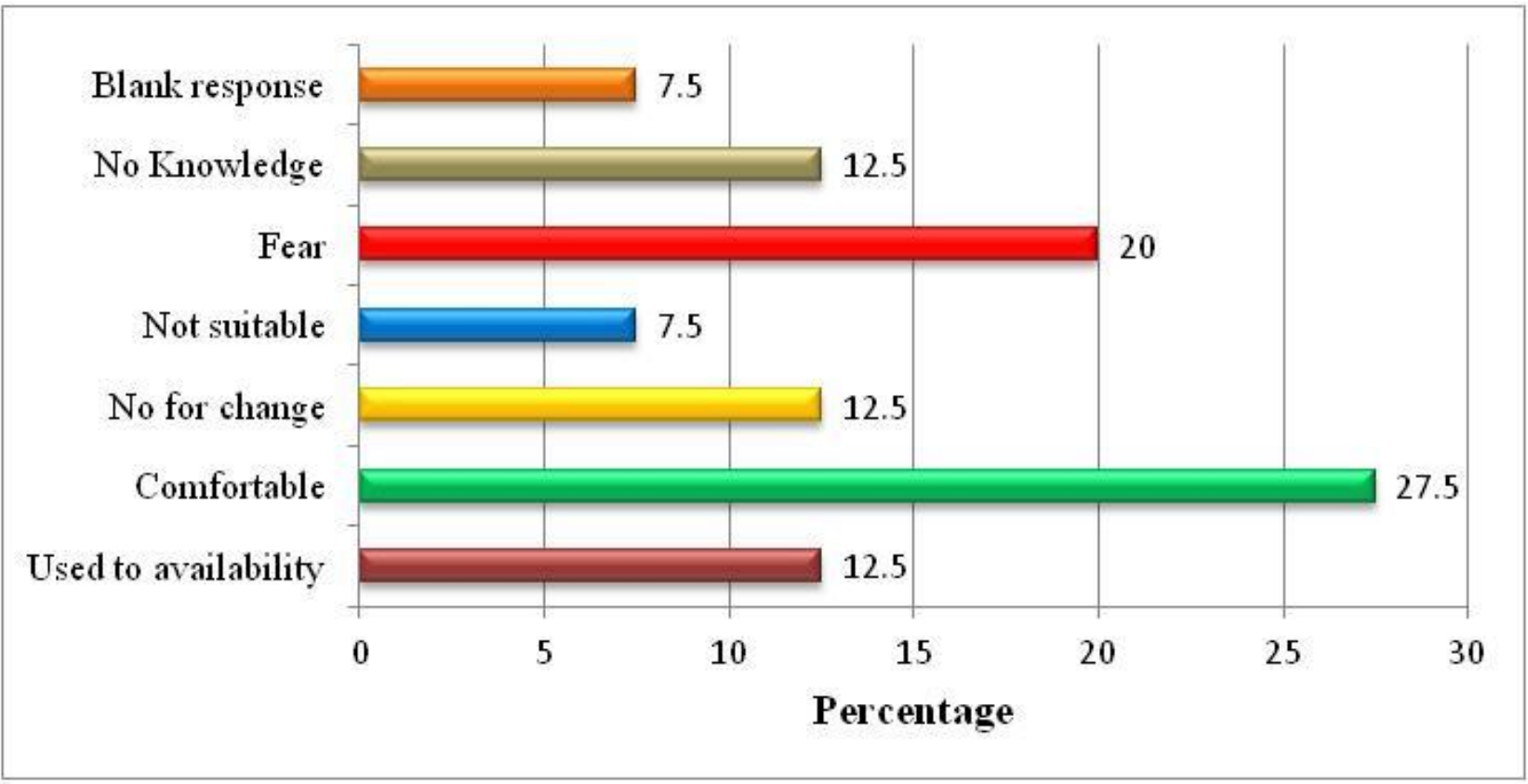

Fig.4 Knowledge of environmental hazards regarding FHP among college girls

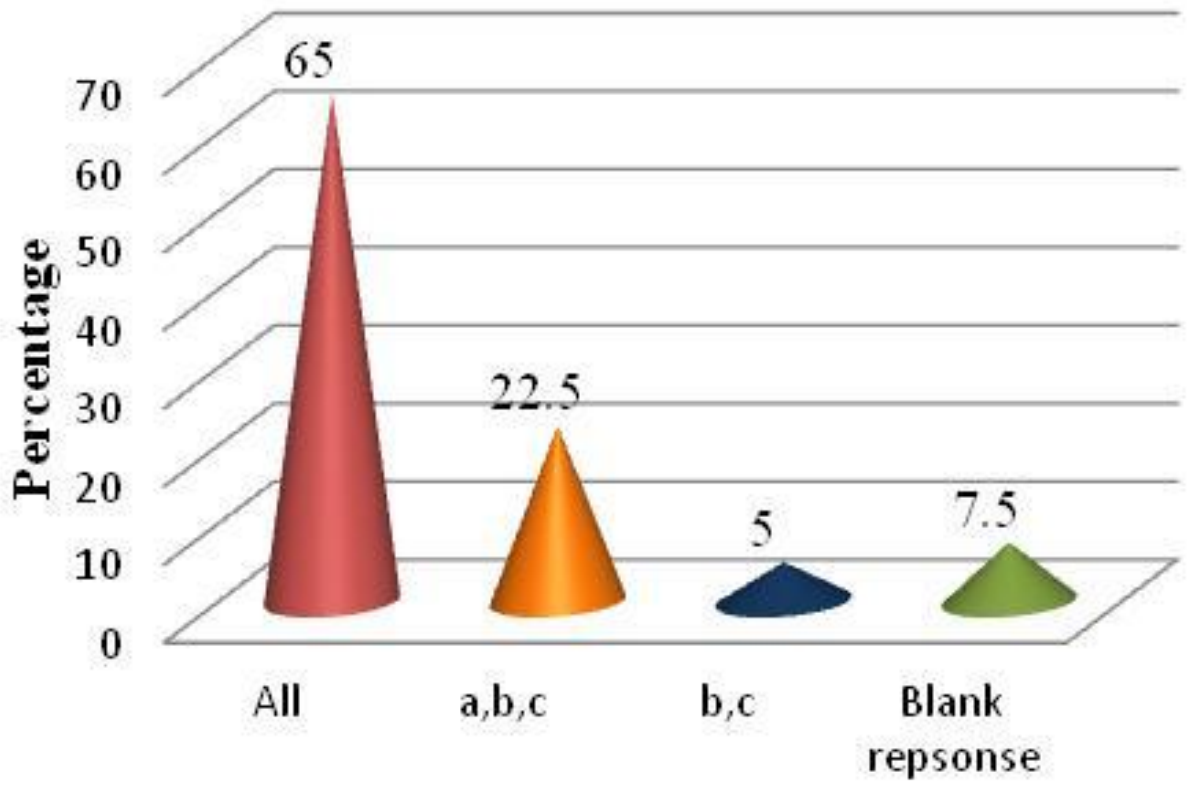

All $\approx \mathrm{a}, \mathrm{b}, \mathrm{c} \backsim \mathrm{b}, \mathrm{c} \backsim$ Blank repsonse

\begin{tabular}{|l|l|}
\hline $\mathbf{a}=$ Non biodegradable & $\mathbf{c}=$ Hazardous to animals \\
\hline $\mathbf{b}=$ Air, water, land pollution & $\mathrm{d}=$ Hazardous to community \\
\hline
\end{tabular}


Table.1 Source of information about FHP

\begin{tabular}{|l|c|c|}
\hline \multicolumn{1}{|c|}{ Information Source } & Frequency & $\%$ \\
\hline Mother & 16 & 40 \\
\hline Mother, Friend, Mass Media & 8 & 20 \\
\hline Relative & 5 & 12.5 \\
\hline Mother, Friend & 4 & 10 \\
\hline Mother, Friend, School & 3 & 7.5 \\
\hline Mother, Friend, Relative & 2 & 5 \\
\hline Mother, Relative & 2 & 5 \\
\hline
\end{tabular}

Table.2 Influence of advertisements on purchase of sanitary pads

\begin{tabular}{|l|c|c|}
\hline \multicolumn{1}{|c|}{ Influence of Advertisement } & Frequency & $\%$ \\
\hline Yes & 24 & 60 \\
\hline No & 14 & 35 \\
\hline Sometimes & 2 & 5 \\
\hline
\end{tabular}

Table.3 Frequency of pad usage per day

\begin{tabular}{|c|c|c|}
\hline No. of pads used per day & Frequency & $\%$ \\
\hline $\mathbf{1}$ & 10 & 25 \\
\hline $\mathbf{2}$ & 18 & 45 \\
\hline $\mathbf{2}$ & 12 & 30 \\
\hline
\end{tabular}

Table.4 Respondents view of appropriate practices to lessen environmental pollution

\begin{tabular}{|l|c|c|}
\multicolumn{1}{|c}{ Practices } & Frequency & \% \\
\hline Proper disposal & 20 & 50 \\
\hline Burn & 6 & 15 \\
\hline Recycle Plastic & 6 & 15 \\
\hline Special Dustbin in the community & 4 & 10 \\
\hline Use Menstrual Cup & 2 & 5 \\
\hline Incineration & 2 & 5 \\
\hline
\end{tabular}

Figure 2 reveals the important factors that governed the respondent's choice of FHP.

It is apparent that a majority of people $(55 \%)$ felt that the sanitary pads were hygienically safe, easy to use, easily available, comfortable, had dry feel and were thin. Around 12.5 per cent were of the opinion that pads were easy to use and comfortable.
Information regarding the influence of advertisements on the respondents was sought.

It can be noted that 60 per cent were influenced by advertisements, while 35 per cent were not (Table 2) and 5 per cent indicated that they are sometimes influenced by advertisements. 
The respondents were very comfortable with sanitary pads and were unwilling to switch over to other types of absorbents like tampons and menstrual cups. Figure 3 indicates the reasons for non-adoption of FHP other than sanitary pads. Although 7.5 per cent of the respondents gave a blank response for nonadoption; 27.5 per cent felt that pads were comfortable, 20 per cent were fearful of tampons and menstrual cups; 12.5 per cent were not willing to change their usage pattern; 12.5 per cent had no knowledge of other absorbents; $7.5 \%$ were used to easy availability of sanitary pads and 7.5 per cent felt that they were not suitable to their life style.

It is interesting to note that cent per cent of the respondents wrap the used sanitary napkins in paper and dispose them daily in dustbin. The disposal of menstruation protection seems to be influenced by location as reported by Bharadwaj and Patkar (2004).

Table 3 shows the number of pads used per day during the menstrual cycle. Around 45 per cent of the girls changed them twice per day and 30 per cent changed three pads per day, while 25 per cent used one pad per day.

The respondents were asked if they knew of environmental hazards of feminine hygiene products. A majority of them said 'Yes' (92.5\%), while 7.5 per cent said 'No'. The affirmative group was asked to elaborate on the environmental hazards (Figure 4). A majority $(65 \%)$ were of the opinion that sanitary pads were non-biodegradable, leads to air, water and land pollution, hazardous to animals and community. There were about 7.5 per cent of blank responses.

All the respondents were asked to give their suggestions (Table 4) regarding the correct practices to be followed to reduce environmental pollution. Half of the respondents felt that the used sanitary pads have to be disposed properly, although they were not clear as to the right method of disposal; 15 per cent felt that used pads could be burnt; another 15 per cent opined that the plastic of the pads could be recycled; 10 per cent felt the need for a special dustbin to be placed in their community so that the municipality could use the right disposal method; 5 per cent felt that use of menstrual cup would lessen the load on the environment; 2.5 per cent were of the opinion that the used pads could be burnt.

The study has attempted to find out the awareness, adoption, usage and disposal pattern of feminine hygiene products among college going students. There is a distinctive lack of proper menstrual management practices as the used sanitary pads find their way into solid waste, thereby leading to environmental pollution (Kaur et al., 2018). Disposal of FHP would be the next big environmental challenge, if not addressed now.

\section{References}

Bharadwaj, S. And Patkar, A. 2004. Menstrual hygiene and management in developing countries: Taking stock. Junction Social, Social Development Consultants report.

Garikipati, S., and Boudot, C. 2017. To pad or not to pad: towards better sanitary care for women in Indian slums. Journal of International Development. 29, 32-51.

Rajanbir Kaur, Kanwaljit Kaur, and Rajinder Kaur, "Menstrual Hygiene, Management, and Waste Disposal: Practices and Challenges Faced by Girls/Women of Developing Countries," Journal of Environmental and Public Health, vol. 2018, Article ID 1730964, 9 pages, 2018. 
Shreya, The Ecological Impact of Feminine Hygiene Products. Available at https://rctom.hbs.org/submission/theecological-impact-of-feminine-hygieneproducts/ [Accessed 14 August 2018].
Van Eijk AM, Sivakami M, Thakkar MB, et al., Menstrual hygiene management among adolescent girls in India: a systematic review and meta-analysis. BMJ Open. 2016; 6(3):e010290. doi:10.1136/bmjopen-2015-010290.

\section{How to cite this article:}

Sirisha Deepthi Sornapudi, Meenu Shrivastava, Shalini Soni and Shweta Jha. 2018. Adoption, Use and Environmental Impact of Feminine Hygiene Products among College Going Girls of Udaipur, India. Int.J.Curr.Microbiol.App.Sci. 7(09): 3719-3725.

doi: https://doi.org/10.20546/ijcmas.2018.709.461 